\title{
Invited Editorial. COVID-19 Vaccine: Hope and reality
}

\author{
Mohamud Sheek-Hussein ${ }^{1}$, Fikri M Abu-Zidan ${ }^{2}$
}

1. Institute of Public Health, College of Medicine and Health Sciences, UAE University, Al-Ain, United Arab Emirates.

2. Department of Surgery, College of Medicine and Health Sciences, UAE University, Al-Ain, United Arab Emirates.

\section{Emails and other details:}

Mohamud Sheek-Hussein: msheekhussein@uaeu.ac.ae, https://orcid.org/0000-0003-4925-2447

Fikri M. Abu-Zidan: fabuzidan@uaeu.ac.ae, https://orcid.org/0000-0003-0143-8568

DOI: https://dx.doi.org/10.4314/ahs.v20i4.3

Cite as: Sheek-Hussein M, Abu-Zidan FM. Invited Editorial. COVID-19 Vaccine: Hope and reality. Afri Health Sci. 2020;20(4):1507-9. bttps:// dx.doi.org/10.4314/abs.v20i4.3

\section{Introduction}

The novel COVID-19 pandemic started at the Chinese province of Hubei in December 2019 after which the WHO declared it to be a public global health emergency. ${ }^{1}$ The COVID-19 virus has a zoonotic source with similarities to other highly infectious zoonotic coronaviruses. COVID-19 infection is highly contagious and continues to spread in both developed and developing countries. ${ }^{2}$ It has caused more than fifty million infected cases and more than one million two hundred fifty thousand deaths worldwide. ${ }^{3}$ Recently, the World Health Organization (WHO) and United Nations Children's Fund (UNICEF) reported an alarming decline in childhood immunization around the world because of the disruption caused by the COVID-19 pandemic. $^{4}$ Immunization significantly reduced disability and death related to vaccine-preventable diseases worldwide. ${ }^{5}$ Delivering essential immunization is important to protect the health, well-being, and economy of a community. Until now, COVID-19 disease does not have effective antiviral drugs nor a fully licensed approved vaccine. Implementing public health measures that aim to prevent the transmission of COVID-19 such as wearing a

\section{Corresponding author: \\ Fikri M Abu-Zidan, \\ Department of Surgery, \\ College of Medicine and \\ Health Sciences,UAE University, \\ Al-Ain, United Arab Emirates \\ E-mail: fabuzidan@uaeu.ac.ae}

facemask, social distancing and frequent hand washing are a real challenge. ${ }^{3}$ COVID-19 severity is increased in those having comorbidities and those having strong immunological reactions. While it is important to study treatment options for COVID-19 disease, an effective vaccine against COVID-19 is more rewarding because it will stop its spread. There is an urgent need for safe, effective, and long-standing high immunogenicity COVID-19 vaccines.

\section{Lessons from history}

Development of a vaccine has always been difficult. It requires extensive experimental and clinical testing before being approved by the regulatory bodies. This may take years before approval. ${ }^{5,6}$ During this long period, it will be difficult for public health measures alone to eliminate the virus. Just to highlight this point, in 1796 Edward Jenner inoculated a 13 year-old-boy with vaccinia virus (cowpox) and demonstrated immunity to smallpox. In 1798, the first smallpox vaccine was developed. Systematic mass immunization resulted in global eradication of smallpox only in 1979. ${ }^{7,8}$ There have been several attempts to develop vaccines against recent emerging viral infections such as the Zika virus, Ebola, SARS and MERS-CoV. These attempts were disappointing. Difficulties encountered were the rapid genetic mutation of the pathogens and finding an appropriate animal model for testing. Similarly, the immune mechanisms against the three most devastating global diseases, malaria, tuberculosis and HIV are still poorly understood. ${ }^{9}$ We have also to stress that the development of a weak immunogenic vaccine could worsen the COVID-19 pandemic if authorities wrongly assume it causes a substantial reduction in risk. ${ }^{10}$ 


\section{One globe one health approach}

The "one globe one health approach" is essential for the global fight against the COVID-19 pandemic. The scientific community and progress in finding a vaccine is affected by using COVID-19 as a political tool between different parties. This delays the world from reaching its similar global target. We must appreciate that mass global immunization is the only way to address the COVID-19 pandemic. Participation in COVID-19 immunization trials will be essential to reduce the impact of COVID-19 disease. The magnitude of participation will depend on the community attitude towards vaccination. Accordingly, vaccine hesitancy in a community must be defined. There is high acceptance for a COVID-19 vaccine in the USA ${ }^{11,12}, \mathrm{EU}^{13,14}$ and China ${ }^{15}$ but this has to be defined in other countries. The cost of giving the immunization in poor countries is a real concern because immunization should be given globally to quickly eliminate the disease and to reduce the chance of genetic mutations.

\section{Changing our strategy}

It is a real challenge to develop vaccines against "complex" infections such COVID-19. Although the vaccine development seems difficult, the reward is huge. This requires innovative thinking. Our knowledge of biotechnology, immunology, genetics and virology is expanding. Furthermore, advancements in molecular engineering and platform technology which were applied in the vaccine development for tuberculosis, Zika, HIV, and Ebola will be tremendously useful in the development of a COVID19 vaccine. ${ }^{16}$ A successful vaccine should cause a proper humoral reaction usually through the organization of proteins from microbes. Therefore, designing effective vaccines requires a shift in our strategy by finding a vaccine that can produce a quick immune response. Vaccination response can be measured by antibody titers. Majority of those who are vaccinated may produce high titers of antibodies. Nevertheless, some may produce no or low levels of protective antibodies (Non or low responders) because of genetic predisposition, immunosuppression, or other disorders. Furthermore, the human body will retain its own memory on how to fight that diseases in the future. Nevertheless, after a while, immunity might decline. Therefore, booster doses may be needed to raise immunity to optimal levels.

\section{The way forward}

We think that getting a COVID-19 vaccine, although it has multiple challenges, is feasible but may take time if it is going to be safe and effective. Currently, there are 45 candidate vaccines in clinical evaluation, and ten more in phases II and III clinical trials. ${ }^{17}$ Which of these rapid developed vaccines will be effective against COVID 19 is still unknown? Developing a vaccine needs proper understanding of the immune response against the COVID-19 virus. ${ }^{18}$ We have to acknowledge that this knowledge is still limited. An effective vaccine would generate a safe reaction producing antibodies to COVID-19 antigens. ${ }^{19}$ Antibody induced protection may be different from the normal defence against viruses because of the resistant naturef COVID-19. Antibodies solely directed towards the SARS-CoV spike (S) protein have been able to counteract the virus and halt infection. ${ }^{20}$ Studies in progress try to define whether the $\mathrm{S}$ protein or its receptor-binding domain (RBD) have comparable value as immunization targets. ${ }^{21}$

Finally, we should be optimistic. The prospect of effective vaccine may be on the horizon. An ongoing clinical trial gave very promising results. Interim analysis of a study on a new vaccine which is given in two doses, showed that it was more than $90 \%$ effective at preventing COVID-19 infection. The vaccine which is a virus messenger RNA enters the human cells and stimulates the production of the coronavirus spike proteins which are the target for the human immune system. Whether this vaccine will give long term immunity or whether it can be used in different patient populations is still unknown. ${ }^{22}$

\section{References}

1. World Health Organization. Novel Coronavirus (2019-nCoV) SITUATION REPORT, 21 JANUARY 2020 Available at https://www.who.int/ docs/default-source/coronaviruse/situation-reports/20200121-sitrep-1-2019-ncov.pdf; (Accessed $10^{\text {th }}$ November 10,2020 )

2. Khan G, Sheek-Hussein M, Al Suwaidi AR, Idris K, Abu-Zidan FM. Novel coronavirus pandemic: A global health threat. Turk J Emerg Med. 2020;20:55-62.

3. European Centre for Disease Prevention and Control. COVID-19 situation update worldwide, as of 12 November 2020 Available at https:/ /www.ecdc.europa. $\mathrm{eu} / \mathrm{en} /$ geographical-distribution-2019-ncov-cases (Accessed 12th November 2020).

4. World Health Organization. WHO and UNICEF warn of a decline in vaccinations during COVID-19. Available on https://www.who.int/news/item/1507-2020-who-and-unicef-warn-of-a-decline-in-vaccinations-during-covid-19; (Accessed 10 ${ }^{\text {th }}$ November $10,2020)$

5. Andre FE, Booy R, Bock HL, Clemens J, Datta SK, 
John TJ, Lee BW, Lolekha S, Peltola H, Ruff TA, Santosham M, Schmitt HJ. Vaccination greatly reduces disease, disability, death and inequity worldwide. Bull World Health Organ. 2008;86:140-6.

6. Hajj Hussein I, Chams N, Chams S, et al. Vaccines Through Centuries: Major Cornerstones of Global Health. Front Public Health. 2015;3:269.

7. Riedel S. Edward Jenner and the history of smallpox and vaccination. Proc (Bayl Univ Med Cent). 2005;18:2125.

8. World Health Organization. No Smallpox, 26 October 1977 to 26 October 1979, Weekly Epidemiological Record: 1979, 54, 329-335.

9. Boraschi D, Abebe Alemayehu M, Aseffa A, Chiodi F, Chisi J, Del Prete G et al. Immunity against HIV/ AIDS, malaria, and tuberculosis during co-infections with neglected infectious diseases: recommendations for the European Union research priorities. PLoS Negl Trop Dis. 2008;2:e255.

10. Krause PR, Fleming TR, Ellenberg SS, Henao-Restrepo AM; WHO Ad Hoc Clinical Trial Expert Group. Maintaining confidentiality of emerging results in COVID-19 vaccine trials is essential. Lancet. 2020 Oct 27:S0140-6736(20)32259-5.

11. Reiter PL, Pennell ML, Katz ML. Acceptability of a COVID-19 vaccine among adults in the United States: How many people would get vaccinated? Vaccine. 2020;38:6500-6507

12. Malik AA, McFadden SM, Elharake J, Omer SB. Determinants of COVID-19 vaccine acceptance in the US. E Clinical Medicine. 2020;26:100495.

13. Fadda M, Albanese E, Suggs LS. When a COVID-19 vaccine is ready, will we all be ready for it? Int J Public Health. 2020;65:711-712.

14. Detoc M, Bruel S, Frappe P, Tardy B, Botelho-Nev- ers E, Gagneux-Brunon A. Intention to participate in a COVID-19 vaccine clinical trial and to get vaccinated against COVID-19 in France during the pandemic. Vaccine. 2020;38:7002-7006.

15. Sun S, Lin D, Operario D. Interest in COVID-19 vaccine trials participation among young adults in China: Willingness, reasons for hesitancy, and demographic and psychosocial determinants. medR $x$ iv [Preprint]. 2020 Jul 14:2020.07.13.20152678. doi: 10.1101/2020.07.13.20152678.

16. Florindo HF, Kleiner R, Vaskovich-Koubi D, Acúrcio RC, Carreira B, Yeini E, Tiram G, Liubomirski Y, Satchi-Fainaro R. Immune-mediated approaches against COVID-19. Nat Nanotechnol. 2020;15:630-645.

17. World Health Organization. Draft landscape of COVID-19 candidate vaccines. Available at https:// www.who.int/publications $/ \mathrm{m} /$ item/draft-landscapeof-covid-19-candidate-vaccines (Accessed November $10,2020)$

18. Oyston P, Robinson K. The current challenges for vaccine development. J Med Microbiol. 2012;61:889-894. 19. Funk CD, Laferrière C, Ardakani A. A Snapshot of the Global Race for Vaccines Targeting SARSCoV-2 and the COVID-19 Pandemic. Front Pharmacol. 2020;11:937.

20. Jeyanathan M, Afkhami S, Smaill F, Miller MS, Lichty BD, Xing Z. Immunological considerations for COVID-19 vaccine strategies. Nat Rev Immunol. 2020;20:615-632.

21. Hotez PJ, Corry DB, Bottazzi ME. COVID-19 vaccine design: the Janus face of immune enhancement. Nat Rev Immunol. 2020;20:347-348.

22. Galaway E. What Pfizer's landmark COVID vaccine results mean for the pandemic. Nature, $9^{\text {th }}$ November 2020. https://www.nature.com/articles/d41586-02003166-8 (Accessed on 11th November 2020). 